Specific status of Echinococcus canadensis (Cestoda Taeniidae) inferred from nuclear and mitochondrial gene sequences

\title{
Yanagida, Tetsuya
}

2017-12

Yanagida , T, Lavikainen , A , Hoberg , E P , Konyaev , S, Ito , A , Sato , M O , Zaikov , V A , Beckmen , K \& Nakao , M 2017, ' Specific status of Echinococcus canadensis (Cestoda Taeniidae) inferred from nuclear and mitochondrial gene sequences ' , International Journal for Parasitology , vol. 47 , no. 14 , pp. 971-979 . https://doi.org/10.1016/j.ijpara.2017.07.001

http://hdl.handle.net/10138/298234

https://doi.org/10.1016/j.ijpara.2017.07.001

publishedVersion

Downloaded from Helda, University of Helsinki institutional repository.

This is an electronic reprint of the original article.

This reprint may differ from the original in pagination and typographic detail.

Please cite the original version. 


\title{
Specific status of Echinococcus canadensis (Cestoda: Taeniidae) inferred from nuclear and mitochondrial gene sequences ${ }^{2}$
}

\author{
Tetsuya Yanagida ${ }^{\mathrm{a}, *}$, Antti Lavikainen ${ }^{\mathrm{b}}$, Eric P. Hoberg ${ }^{\mathrm{c}}$, Sergey Konyaev ${ }^{\mathrm{d}}$, Akira Ito ${ }^{\mathrm{e}}$, \\ Marcello Otake Sato ${ }^{\mathrm{f}}$, Vladimir A. Zaikov ${ }^{\mathrm{g}}$, Kimberlee Beckmen ${ }^{\mathrm{h}}$, Minoru Nakao ${ }^{\mathrm{e}}$ \\ a Laboratory of Veterinary Parasitology, Joint Faculty of Veterinary Medicine, Yamaguchi University, Yamaguchi, Japan \\ ${ }^{\mathrm{b}}$ Immunobiology Program/Department of Bacteriology and Immunology, Faculty of Medicine, University of Helsinki, Finland \\ ${ }^{c}$ US Department of Agriculture, Agricultural Research Service, Animal Parasitic Diseases Laboratory, Beltsville, MD, USA \\ ${ }^{\mathrm{d}}$ Institute Systematics and Ecology of Animals, Siberian Branch Russian Academy of Sciences, Novosibirsk, Russia \\ e Department of Parasitology, Asahikawa Medical University, Asahikawa, Japan \\ ${ }^{\mathrm{f}}$ Department of Tropical Medicine and Parasitology, Dokkyo Medical University, Tochigi, Japan \\ ${ }^{g}$ Kenozero National Park, Arkhangelsk, Russia \\ ${ }^{\mathrm{h}}$ Department of Fish and Game, Fairbanks, AK, USA
}

\section{A R T I C L E I N F O}

\section{Article history:}

Received 20 January 2017

Received in revised form 27 June 2017

Accepted 3 July 2017

Available online 7 August 2017

\section{Keywords:}

Echinococcus canadensis

cox 1

pold

pepck

Nuclear-mitochondrial discordance

\begin{abstract}
A B S T R A C T
The specific status of Echinococcus canadensis has long been controversial, mainly because it consists of the mitochondrial lineages G6, G7, G8 and G10 with different host affinity: G6 (camel strain) and G7 (pig strain) with domestic cycles and G8 (cervid strain) and G10 (Fennoscandian cervid strain) with sylvatic or semi-domestic cycles. There is an argument whether the mitochondrial lineages should be recognised as separate species which correspond to the biological or epidemiological aggregation. In the present study, the specific status of E. canadensis was investigated using mitochondrial DNA and single copy nuclear DNA markers. Nucleotide sequences of complete mitochondrial cytochrome $c$ oxidase subunit 1 ( $\operatorname{cox} 1)$ and partial nuclear phosphoenolpyruvate carboxykinase (pepck) and DNA polymerase delta (pold) were determined for 48 isolates of $E$. canadensis collected from different hosts in a wide range of regions. The mitochondrial phylogeny of cox 1 showed that all the isolates were clearly divided into three clades corresponding to G6/G7, G8 and G10. Five and three alleles were confirmed at pepck and pold loci, respectively. These alleles were generally divided into two groups corresponding to G6/G7 or G8 and G10. However, allele sharing was confirmed among individuals belonging to different lineages. The allele sharing occurred primarily in regions where different mitochondrial DNA lineages were found in sympatry. The resultant nuclear mitochondrial discordance suggests the genetic exchangeability among E. canadensis isolates belonging to different lineages. An apparently mosaic parasite fauna that reflects faunal mixing due to natural and anthropogenic disturbance, including introductions and invasion, precludes us from designating each of G6/G7, G8 and G10 into a different species.
\end{abstract}

(C) 2017 Australian Society for Parasitology. Published by Elsevier Ltd. All rights reserved.

\section{Introduction}

Echinococcosis or hydatidosis is one of the most serious helminthic zoonoses with a worldwide distribution. It affects various internal organs, particularly liver, of terrestrial mammals including livestock, wildlife and humans. The causative agents are the cestodes belonging to the genus Echinococcus Rudolphi, 1801 (Cestoda: Taeniidae). Echinococcus spp. utilise canids or felids as

\footnotetext{
Note: Nucleotide sequence data reported in this paper are available in DDBJ/ EMBL/GenBank databases under the accession nos. LC184603-LC184606.

* Corresponding author at: Yoshida 1677-1, Yamaguchi 753-8511, Japan.

E-mail address: yanagi-t@yamaguchi-u.ac.jp (T. Yanagida).
}

definitive hosts and a variety of ungulates, rodents or lagomorphs as intermediate hosts.

Taxonomy of Echinococcus has continuously been revised based on morphology, ecological features (hosts) and molecular phylogeny (Nakao et al., 2013a, b; see review in Lymbery, 2017). Echinococcus granulosus sensu lato (s.l.) is the most prevalent morphospecies in the genus with a worldwide distribution. It causes unilocular hydatid cysts in a variety of ungulate intermediate hosts, and hence the species complex has been divided into the 'strains' based to a large degree on the host affinity (Eckert et al., 2001; Thompson and McManus, 2002). The taxonomic status of these strains has been verified by molecular analyses, and nine mitochondrial DNA (mtDNA) lineages (G1-G8 and G10) have been 
demonstrated and formally recognised (Bowles et al., 1992, 1994; Bowles and McManus, 1993; Lavikainen et al., 2003). These mitochondrial lineages have conventionally been referred as "genotypes". In addition to E. granulosus sensu stricto (s.s.) (for G1 and G2 sheep strains and G3 buffalo strain), nominal taxa currently considered as valid and characterised by typical unilocular hydatid cysts include Echinococcus equinus (G4 horse strain), Echinococcus ortleppi (G5 cattle strain), Echinococcus canadensis (G6 camel strain, G7 pig strain, G8 cervid strain and G10 Fennoscandian cervid strain) and Echinococcus felidis (lion strain) (see review in Nakao et al., 2013a). Although taxonomic diversity within the genus has mostly been settled following intensive molecular phylogenetic and phylogeographic analyses using parasite isolates from a variety of hosts worldwide, the status of $E$. canadensis remains a topic of debate (Nakao et al., 2013a, 2015; Lymbery et al., 2015a,b; Lymbery 2017; Ito et al., 2017).

Echinococcus canadensis was originally established and described as a variant of E. granulosus with hydatids in Eurasian reindeer, Rangifer tarandus tarandus, from an introduced population at Aklavik, Northwest Territories, Canada (Cameron, 1960), and later validated as a subspecies of E. granulosus (Sweatman and Williams, 1963). Concurrently, another subspecies of E. granulosus was described in free-ranging and endemic cervid intermediate hosts (moose, Alces alces gigas) from northern Ontario, Canada (Sweatman and Williams, 1963). These two North American subspecies were formally recognised as Echinococcus granulosus canadensis and Echinococcus granulosus borealis, occurring in a semi-domestic wolf/dog-reindeer cycle and a wolf-moose sylvatic cycle, respectively (Sweatman and Williams, 1963). Cestodes attributable to these subspecies apparently were prepared as stained, whole-mounted, specimens that were used as the basis for descriptions and differential diagnosis. However, as far as we examined, these slides have not been located in North America or in New Zealand where these studies were conducted. The only remaining specimens were formalin-fixed and ethanol-preserved strobilate tapeworms from domestic dogs experimentally infected with metacestodes of reindeer or moose (Sweatman and Williams, 1963). These fluid specimens were labelled as types of E. granulosus canadensis (USNPC 59725) and E. granulosus borealis (USNPC 59724), and archived in the former United States National Parasite Collection (USNPC).

Although the validity of these subspecies was denied by Rausch (2003) due to their assumed sympatric distribution, E. canadensis was subsequently resurrected as a putative species (containing $E$. g. canadensis and E. g. borealis) consisting of the G6, G7, G8 and G10 of $E$. granulosus based on molecular phylogenetic analysis using mtDNA genome sequences (see review in Nakao et al., 2013a). There still remains, however, a debate whether the mitochondrial lineages should be treated as $2-3$ separate species with different biological and epidemiological features, or as a complex of poorly differentiated populations within a single species influenced by widespread translocation, introduction and gene flow at some geographic localities and in regions of primary and secondary contact (Nakao et al., 2013a,b, 2015; Lymbery et al. 2015a,b; Ito et al., 2017).

Resolution of taxonomic status in this assemblage has been hindered by the absence of conclusive evidence. For example, the putative genetic relationships among E. canadensis mitochondrial lineages have been evaluated primarily based on sequences derived from mtDNA and generally there has been an absence of sequence data from known strobilate adults linked to voucher specimens. To draw definitive conclusions on the specific status of $E$. canadensis, it is essential to use nuclear DNA (nDNA) markers for the investigation of genetic exchangeability among $E$. canadensis lineages, especially in the regions where different lineages are distributed in sympatry, such as in the Russian Far East, North
America and Mongolia (Thompson et al., 2006; Moks et al., 2008; Himsworth et al., 2010; Ito et al., 2013, 2017; Konyaev et al., 2013; Schurer et al., 2013). In the present study, genetic relationships among the mitochondrial lineages of $E$. canadensis were investigated using mtDNA and single copy nDNA markers. Isolates of $E$. canadensis collected from a variety of host animals in a wide range of regions were examined. Furthermore, a molecular identification was attempted to clarify the mitochondrial lineages of the archival type specimens of E. granulosus canadensis and E. granulosus borealis deposited by Sweatman and Williams (1963).

\section{Materials and methods}

\subsection{Geographic isolates and DNA sequencing}

A total of 48 isolates of $E$. canadensis were examined for the two nuclear gene markers in this study. The specimens were collected from various animals, including humans, in a wide range of geographic areas (Table 1). Some of them were previously used for the mtDNA analyses and the detailed data have already been published. Parasite specimens were preserved in $70-100 \%$ ethanol until DNA extraction. The genomic DNA of each parasite isolate was extracted from a single cyst or an adult tapeworm, by using a spin column purification kit (DNA Mini kit or DNeasy Tissue kit, Qiagen, Germany). Alkaline lysates were also made for some tapeworms as reported previously (Hüttner et al., 2008). Extracted DNA or the crude lysate was used as a template for PCR. For the mtDNA gene marker, cytochrome $c$ oxidase subunit I (cox1) was amplified by PCR and the complete cox1 gene sequences were determined using previously reported primer pairs under the same conditions (Hüttner et al., 2008). For nDNA markers, a part of phosphoenolpyruvate carboxykinase (pepck) and DNA polymerase delta (pold) were selected, for their single-copy presence in Echinococcus multilocularis (Echinococcus genome project, Wellcome Trust Sanger Institute, UK, http://www.sanger.ac.uk/) and usefulness in differentiating E. canadensis lineages (Knapp et al., 2011). These nDNA gene markers were amplified by previously reported and newly designed primers: pepck F1 (5'-ACC GAG ACC AAG CTC ACA-3') and pepck R (5'-AGC CCA TTC AAT CAC ACG GAT ATT-3') (Knapp et al., 2011), pold F1 (5'-CTA AGC GGA ATT ATC ATT CC-3') and pold R1 (5'-CAA CGA CTA ACA GTA TTG ACA-3'). The primers were designed to amplify regions including introns to increase the chance of finding variations. PCR was performed in $20 \mu \mathrm{L}$ containing 0.5 units of ExTaq Hot Start Version (TaKaRa, Japan), $0.2 \mathrm{mM}$ of dNTP, $1 \times$ Ex Taq Buffer with a final $\mathrm{MgCl}_{2}$ concentration of $2.0 \mathrm{mM}$, 15 pmol of each primer and $1.0 \mu \mathrm{L}$ of genomic DNA. PCR amplification consisted of initial denaturation of $94^{\circ} \mathrm{C}$ for $2 \mathrm{~min}, 40$ cycles of $94{ }^{\circ} \mathrm{C}$ for $15 \mathrm{~s}, 55^{\circ} \mathrm{C}$ for $15 \mathrm{~s}$ and $72{ }^{\circ} \mathrm{C}$ for $30 \mathrm{~s}$, and a terminal extension at $72{ }^{\circ} \mathrm{C}$ for $1 \mathrm{~min}$. PCR products were treated with illustra ExoProStar (GE Healthcare, UK) to remove excess primers and dNTPs, and subsequently sequenced directly with a BigDye Terminator v3.1 and a 3500 DNA sequencer (Life Technologies, USA). When double peaks were confirmed in the sequencing of nuclear genes, purified PCR products were ligated into a pGEM-T plasmid vector (Promega, USA) and subsequently introduced into Escherichia coli DH5 $\alpha$. At least 10 colonies were picked up from agar plates and their insert DNAs were sequenced directly to confirm allelic polymorphism.

\subsection{Archival analysis of the museum specimens}

Formalin-fixed adult worms of E. granulosus canadensis and E. granulosus borealis, deposited by Sweatman and Williams (1963) in the USNPC curated by the United States Department of Agriculture (now Smithsonian Institution, National Museum of Natural 
Table 1

Isolates of Echinococcus ortleppi and Echinococcus canadensis mitochondrial DNA lineages used for molecular analyses.

\begin{tabular}{|c|c|c|c|c|c|c|c|}
\hline \multirow[t]{2}{*}{ Mitochondrial lineages } & \multirow[t]{2}{*}{ Localities } & \multirow[t]{2}{*}{ Parasite stages $^{\mathrm{a}}$ (hosts) } & \multicolumn{2}{|c|}{ Nuclear gene alleles } & \multirow[t]{2}{*}{ cox1 haplotypes } & \multirow{2}{*}{$\begin{array}{l}\text { Accession } \\
\text { No. of } \operatorname{cox} 1\end{array}$} & \multirow[t]{2}{*}{ References for $\operatorname{cox} 1$ sequences } \\
\hline & & & pepck & pold & & & \\
\hline G5 (E. ortleppi) & Argentina & & E. ortleppi & E. ortleppi & E. ortleppi & AB235846 & Nakao et al. (2007) \\
\hline G6 & Kazakhstan & L (camel) & A & A & EcG6 & AB208063 & Nakao et al. (2007) \\
\hline G6 & Mongolia & $A($ wolf $)$ & A & A & EcMGL1 & AB813182 & Ito et al. (2013) \\
\hline G6 & Mongolia & A (wolf) & A & A & EcMGL2 (=EcRUS1) & AB813183 & Ito et al. (2013) \\
\hline G6 & Mongolia & A (wolf) & A & A & EcMGL2 (=EcRUS1) & AB813183 & Ito et al. (2013) \\
\hline G6 & Mongolia & A (wolf) & A & A & EcMGL2 (=EcRUS1) & AB813183 & Ito et al. (2013) \\
\hline G6 & Asian Russia & L (human) & A & A & EcRUS1 (=EcMGL2) & AB688142 & Konyaev et al. (2012) \\
\hline G6 & Asian Russia & $A$ (wolf) & A & A & EcRUS2 & AB777909 & Nakao et al. (2013b) \\
\hline G6 & Asian Russia & A (wolf) & $\mathrm{E}$ & n.d. & EcRUS1 (=EcMGL2) & AB688142 & Nakao et al. (2013b) \\
\hline G6 & Far East Russia & L (reindeer) & $\mathrm{C}$ & $\mathrm{C}$ & EcRUS1 (=EcMGL2) & AB688142 & Nakao et al. (2013b \\
\hline G6 & Ethiopia & $\mathrm{L}$ (camel) & A & A & EcETH2 & AB777923 & Nakao et al. (2013b) \\
\hline G6 & Ethiopia & L (camel) & A & A & EcETH1 & AB777922 & Nakao et al. (2013b) \\
\hline G6 & Mongolia & L (camel) & A & A & EcMGL16 & LC184603 & This study \\
\hline G6 & Peru & L (goat) & A & A & EcRUS1 (=EcMGL2) & AB688142 & Nakao et al. (2013b) \\
\hline G6 & Peru & L (goat) & A & A & EcRUS1 (=EcMGL2) & AB688142 & Nakao et al. (2013b) \\
\hline G6 & Peru & L (goat) & A & A & EcRUS1 (=EcMGL2) & $\mathrm{AB} 688142$ & Nakao et al. (2013b) \\
\hline G6 & Peru & L (goat) & A & A & EcRUS1 (=EcMGL2) & AB688142 & Nakao et al. (2013b) \\
\hline G7 & Peru & $\mathrm{L}$ (pig) & $\mathrm{B}$ & A & EcPER1 & $\mathrm{AB} 777924$ & Nakao et al. (2013b) \\
\hline G7 & Peru & L (pig) & $\mathrm{B}$ & A & EcPER2 & AB777925 & Nakao et al. (2013b) \\
\hline G7 & Poland & L (pig) & $\mathrm{B}$ & A & EcG7 & AB235847 & Nakao et al. (2007) \\
\hline G8 & Far East Russia & $\mathrm{L}$ (moose) & $\mathrm{E}$ & $\mathrm{C}$ & EcRUS3 & AB777910 & Nakao et al. (2013b) \\
\hline G8 & Far East Russia & $\mathrm{L}$ (moose) & $\mathrm{E}$ & $\mathrm{C}$ & EcRUS3 & AB777910 & Nakao et al. (2013b) \\
\hline G8 & Far East Russia & $A$ (wolf) & $\mathrm{E}$ & $\mathrm{C}$ & EcRUS3 & AB777910 & Nakao et al. (2013b) \\
\hline G8 & European Russia & $\mathrm{L}$ (moose) & $\mathrm{C}$ & $\mathrm{B}$ & EcRUS8 & LC184604 & This study \\
\hline G8 & European Russia & $\mathrm{L}$ (moose) & $\mathrm{C}$ & $\mathrm{B}$ & EcRUS8 & LC184604 & This study \\
\hline G8 & European Russia & $\mathrm{L}$ (moose) & $\mathrm{C}$ & $\mathrm{B}$ & EcRUS8 & LC184604 & This study \\
\hline G8 & Alaska, USA & $\mathrm{L}$ (moose) & $\mathrm{C}$ & $\mathrm{B}$ & EcG8 & AB235848 & Nakao et al. (2007) \\
\hline G10 & Mongolia & A (wolf) & A & A & EcMGL3 & AB813184 & Ito et al. (2013) \\
\hline G10 & Mongolia & A (wolf) & A & A & EcMGL3 & AB813184 & Ito et al. (2013) \\
\hline G10 & Mongolia & A (wolf) & $\mathrm{C} / \mathrm{E}$ & $\mathrm{C}$ & EcMGL4 & AB813185 & Ito et al. (2013) \\
\hline G10 & Mongolia & A (wolf) & $\mathrm{C} / \mathrm{E}$ & $\mathrm{C}$ & EcMGL4 & AB813185 & Ito et al. (2013) \\
\hline G10 & Far East Russia & $\mathrm{L}$ (moose) & $\mathrm{E}$ & $\mathrm{B} / \mathrm{C}$ & EcRUS4 & AB777911 & Nakao et al. (2013b) \\
\hline G10 & European Russia & $\mathrm{L}$ (moose) & $\mathrm{C}$ & B & EcG10 & AB745463 & This study \\
\hline G10 & European Russia & $\mathrm{L}$ (moose) & $\mathrm{C}$ & B & EcG10 & $\mathrm{AB} 745463$ & This study \\
\hline G10 & European Russia & $\mathrm{L}$ (moose) & $\mathrm{C}$ & $\mathrm{B}$ & EcG10 & AB745463 & This study \\
\hline G10 & European Russia & $\mathrm{L}$ (moose) & $\mathrm{C}$ & $\mathrm{B}$ & EcG10 & AB745463 & This study \\
\hline G10 & European Russia & $\mathrm{L}$ (moose) & $\mathrm{C}$ & $\mathrm{B}$ & EcRUS9 & LC184605 & This study \\
\hline G10 & European Russia & $\mathrm{L}$ (moose) & $\mathrm{C}$ & $\mathrm{B}$ & EcG10 & AB745463 & Nakao et al. (2013b) \\
\hline G10 & European Russia & $\mathrm{L}$ (moose) & $\mathrm{C}$ & $\mathrm{B}$ & EcG10 & $\mathrm{AB} 745463$ & Nakao et al. (2013b) \\
\hline G10 & Finland & A (wolf) & $\mathrm{C}$ & $\mathrm{B}$ & EcG10 & AB745463 & This study \\
\hline G10 & Finland & A (wolf) & $\mathrm{C}$ & $\mathrm{B}$ & EcG10 & $\mathrm{AB} 745463$ & This study \\
\hline G10 & Finland & L (moose) & $\mathrm{C}$ & B & EcG10 & AB745463 & Nakao et al. (2013b) \\
\hline G10 & Finland & $\mathrm{L}$ (moose) & $\mathrm{C}$ & $\mathrm{B}$ & EcG10 & AB745463 & Nakao et al. (2013b) \\
\hline G10 & Finland & $\mathrm{L}$ (moose) & $\mathrm{C}$ & $\mathrm{B}$ & EcG10 & AB745463 & Nakao et al. (2013b) \\
\hline G10 & Alaska, USA & $\mathrm{L}$ (moose) & $\mathrm{D}$ & $\mathrm{B}$ & EcUSA1 & AB777926 & This study \\
\hline G10 & Alaska, USA & L (caribou) & $\mathrm{D}$ & $\mathrm{B}$ & EcUSA3 & LC184606 & This study \\
\hline G10 & Alaska, USA & $\mathrm{L}$ (moose) & $\mathrm{D}$ & $\mathrm{B}$ & EcUSA1 & AB777926 & Nakao et al. (2013b) \\
\hline G10 & Alaska, USA & $\mathrm{L}$ (moose) & $\mathrm{C}$ & $\mathrm{B}$ & EcUSA2 & AB777927 & Nakao et al. (2013b) \\
\hline G10 & Alaska, USA & $\mathrm{L}$ (moose) & $C / D$ & $\mathrm{~B}$ & EcUSA2 & AB777927 & Nakao et al. (2013b) \\
\hline
\end{tabular}

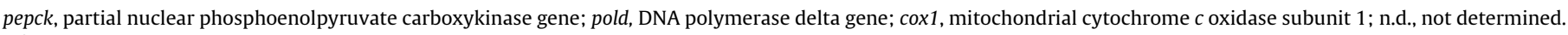

a Parasite stages as L, larva; A, adult.

History, USA), were subjected to molecular analysis. Specimen numbers representing tapeworms among designated types included USNPC 59724 for E. granulosus borealis, and USNPC 59725 for E. granulosus canadensis. Five worms from each specimen vial were used for DNA extraction. Parasite DNAs were extracted using a QIAamp DNA FFPE Tissue Kit (Qiagen). Extracted DNA was used for the subsequent PCR. Due to the degradation of DNA, it is difficult to obtain long fragments of DNA from formalin-preserved specimens. Therefore, PCR primers were designed to amplify short (100-200 bp) fragments, based on the cox 1 sequences of $E$. canadensis. Primer information is provided in the Supplementary Table S1. These fragments were expected to include nucleotide positions which were variable among different mitochondrial lineages and able to distinguish them. PCR amplification consisted of initial denaturation of $94^{\circ} \mathrm{C}$ for $2 \mathrm{~min}$, 40 cycles of $94{ }^{\circ} \mathrm{C}$ for $15 \mathrm{~s}, 45-50{ }^{\circ} \mathrm{C}$ for $15 \mathrm{~s}$ and $72{ }^{\circ} \mathrm{C}$ for $30 \mathrm{~s}$, and a final extension at $72{ }^{\circ} \mathrm{C}$ for $1 \mathrm{~min}$. PCR products were visualised by electrophoresis using $2.0 \%$ agarose gel. DNA of $E$. canadensis $\mathrm{G} 10$ was used as a positive control in every trial.

\subsection{DNA analysis}

Nucleotide sequences were edited by using Geneious Pro software ver. 7.0.4 (created by Biomatters, available from http:// www.geneious.com/). A BLAST search was performed for cox1 gene sequences to identify the mtDNA lineage of each isolate. Then, the sequences were aligned by Clustal W 2.0 (Larkin et al., 2007) with the cox1 gene sequences of E. canadensis and E. ortleppi in DDBJ/ EMBL/GenBank databases by MEGA 6 (Tamura et al., 2013) and a phylogenetic tree was inferred by neighbour-joining method under the Kimura's two-parameter model (Kimura, 1980) with the gamma setting of 0.5 using PAUP 4.0b (Swofford, 2002). The tree 
robustness was tested by bootstrapping with 1000 replicates. A cox1 gene sequence of $E$. multilocularis was used as an outgroup. For the nuclear gene markers, obtained sequences were aligned and the allelic polymorphism was examined. Nucleotide sequences of pepck and pold alleles confirmed in E. canadensis were compared with those of other Echinococcus spp. (DNA database accession Nos. FN567985-FN567992 for pepck and FN568356-FN568363 for pold) (Knapp et al., 2011). All the alignment files are available online (doi:10.17632/cs45cv8bgb.1).

\section{Results}

\section{1. mtDNA phylogeny}

In the present study, 48 isolates of E. canadensis collected from different hosts and regions were examined (Table 1 ). All specimens were used for the sequencing of the nuclear genes (pepck and pold). Mitochondrial lineages were determined for 13 new specimens; others had already been identified in previous studies. Among the 48 specimens, 19 , seven and 22 isolates were identified as G6/G7, G8 and G10 mtDNA, respectively (G6 and G7 are hereinafter referred to as $\mathrm{G} 6 / \mathrm{G} 7$ due to their sequence resemblance). Four new mtDNA haplotypes were obtained in the present study and two of them were identified as G10, and one each as G6/G7 and G8. The phylogenetic analysis of the cox1 sequences shows that the mtDNA haplotypes of E. canadensis can be clearly divided into three monophyletic clades corresponding to G6/G7, G8 and G10, in which G6/G7 and G10 are the sister lineages (Fig. 1) as previously demonstrated (Lavikainen et al., 2006; Moks et al., 2008; Nakao et al., 2013a, b). Maximum pairwise divergence values within each mitochondrial lineage (G6/G7, G8 and G10) were $0.5 \%, 1.1 \%$ and $0.7 \%$, respectively. On the other hand, pairwise divergence values were $1.8-2.2 \%$ between G6/G7 and G10, 2.7$3.5 \%$ between G6/G7 and G8, and 2.7-3.6\% between G8 and G10. Although the monophyly of the mtDNA haplotypes obtained from pigs in Poland and Peru (EcG7, EcPER 1 and EcPER2) was shown, the clade was nested within the larger monophyletic clade consisting of G6 and G7. Among G10 haplotypes, EcMGL3 collected from a wolf in Mongolia was sister to all the other haplotypes, which were divided into Alaskan and Eurasian clades.

\subsection{Nuclear DNA analysis}

\subsubsection{Sequence variations in $n D N A$ markers}

In the pepck and pold loci, five (pepck A-E) and three (pold A-C) alleles were confirmed and the lengths of the nucleotide sequence of the alleles were $525-528$ bp and 689 bp, respectively (Figs. 2 and 3). These alleles were not identical to any of other Echinococcus spp. in the database, although only one allele was available for each species (Supplementary Figs. S1 and S2). The nucleotide positions 269-349 in pepck and 1-105 and 480-689 in pold are introns. The nucleotide sequence of pold was not determined for the isolate in wolf from Asian Russia (Altai region in West Siberia), because PCR did not yield amplicons (Table 1 ). At the pepck locus, mutations were found both in the exons and intron, and all except one were synonymous substitutions (Fig. 2). At the pold locus, all mutations were in the introns (Fig. 3).

\subsubsection{Characteristics of pepck locus}

Among the pepck alleles, only one nucleotide difference was observed between E. ortleppi and pepck A, between pepck $\mathrm{B}$ and $\mathrm{E}$, and between pepck C and D (Fig. 2). Pepck B was obtained only from the isolates collected from pigs, namely G7, in Peru and Poland (Fig.4a, Table 1). Pepck D was exclusively confirmed in the isolates of G10 in moose (Alces alces gigas) and barren-ground caribou (Ran-

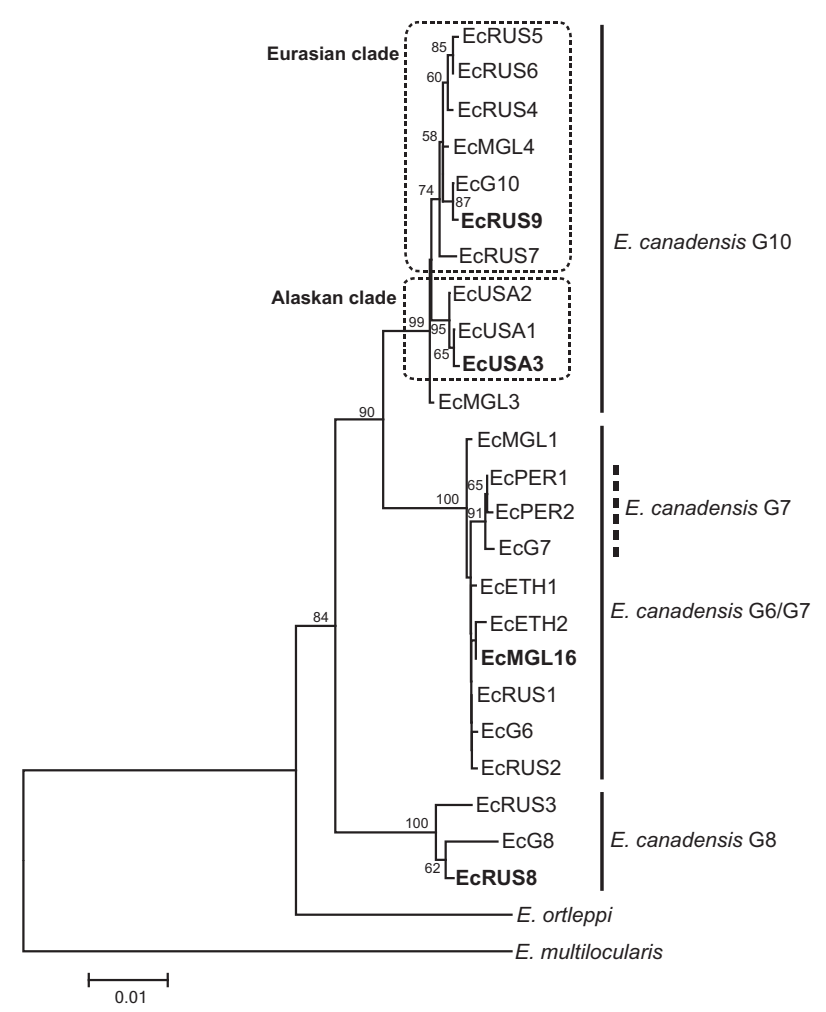

Fig. 1. A neighbour-joining tree of Echinococcus canadensis mitochondrial lineages inferred based on the mitochondrial cytochrome $c$ oxidase subunit 1 (cox1) gene sequences. The names of haplotypes newly confirmed in this study are shown in bold. Numbers on the nodes are the bootstrap values.

gifer tarandus granti) from Alaska. While pepck B and D were unique to G7 and G10, respectively, and focally distributed in a region or a host species, pepck $\mathrm{A}, \mathrm{C}$ and $\mathrm{E}$ were shared by different mtDNA lineages. Pepck A was shared among most of G6 from a variety of hosts worldwide, and two isolates of G10 in wolves from Mongolia. Pepck C showed a Holarctic distribution among G6, G8 and G10 in moose, reindeer and wolves. Pepck E was also shared among G6, G8 and G10 in moose and wolves from the Palearctic. In Mongolia, three alleles (pepck A, C and E) were sympatrically distributed in the Zavkhan province. Two adult worms in wolves from Mongolia and a hydatid cyst in a moose in Alaska proved to be heterozygous, both the adult worms with $\mathrm{C} / \mathrm{E}$ alleles, and the cyst with C/D alleles.

\subsubsection{Characteristics of pold locus}

Among the pold alleles, pold A was distributed worldwide (Fig. 4b, Table 1). It was shared among G6, G7 and G10 from humans, domestic ungulates and wild wolves. Pold B showed a Holarctic distribution (Alaska and northern Europe) among G8 and G10, and pold C was confirmed in G6, G8 and G10 from Mongolia and the Russian Far East. Both alleles were mostly shared among the parasite isolates collected from wild animals such as moose, reindeer/caribou and wolves.

\subsubsection{Combined data of pepck and pold loci}

When two genes were combined, seven nDNA haplotypes were confirmed. The notation of the haplotypes was made by the combination of the alphabetical numbers of pepck and pold alleles (e.g., AA = pepck $\mathrm{A}$ and pold A). Most of the G6 examined in this study possessed the haplotype AA (Fig. 4c, Table 1). This haplotype was found from livestock intermediate hosts (camel and goat), wild wolves, a patient with cystic echinococcosis (CE) in the Altai 


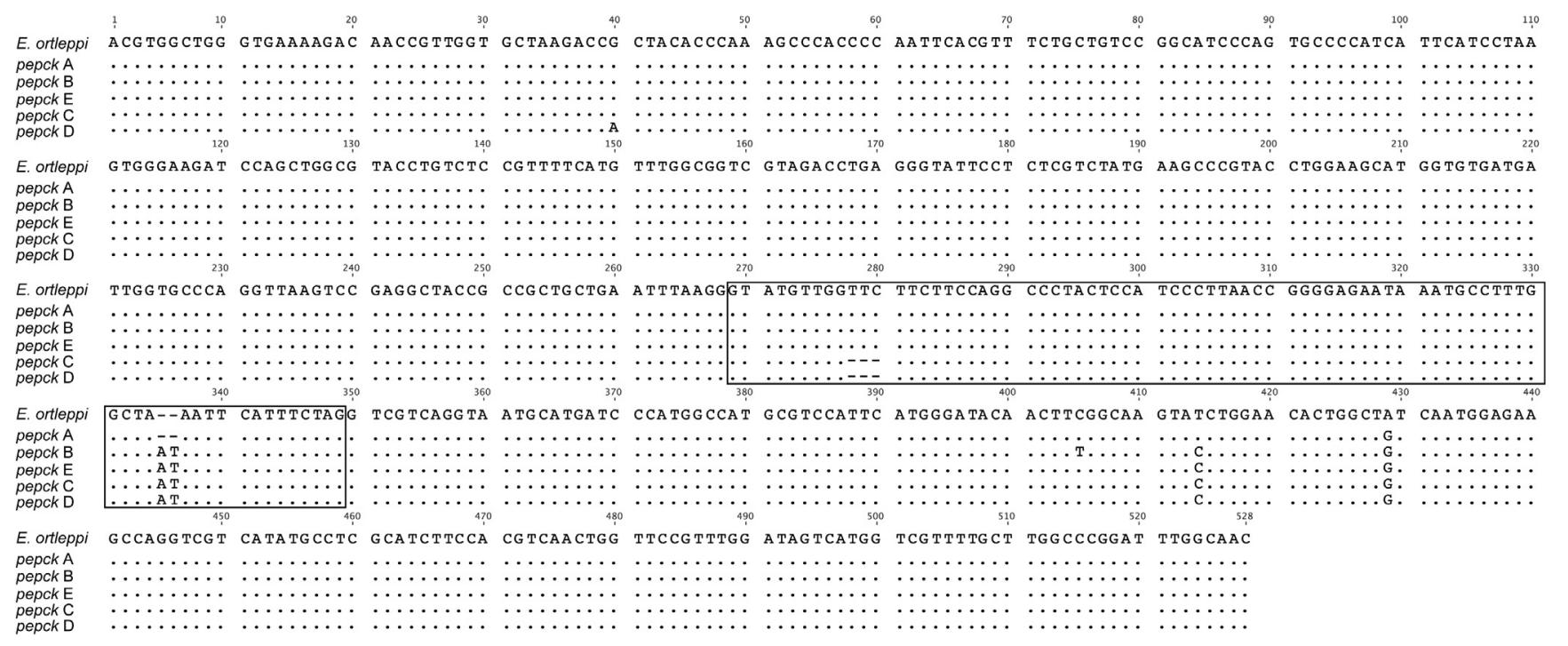

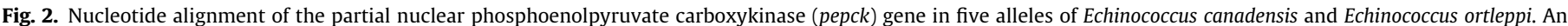
intron is located at nucleotide positions 269-349 (a framed box in the alignment).

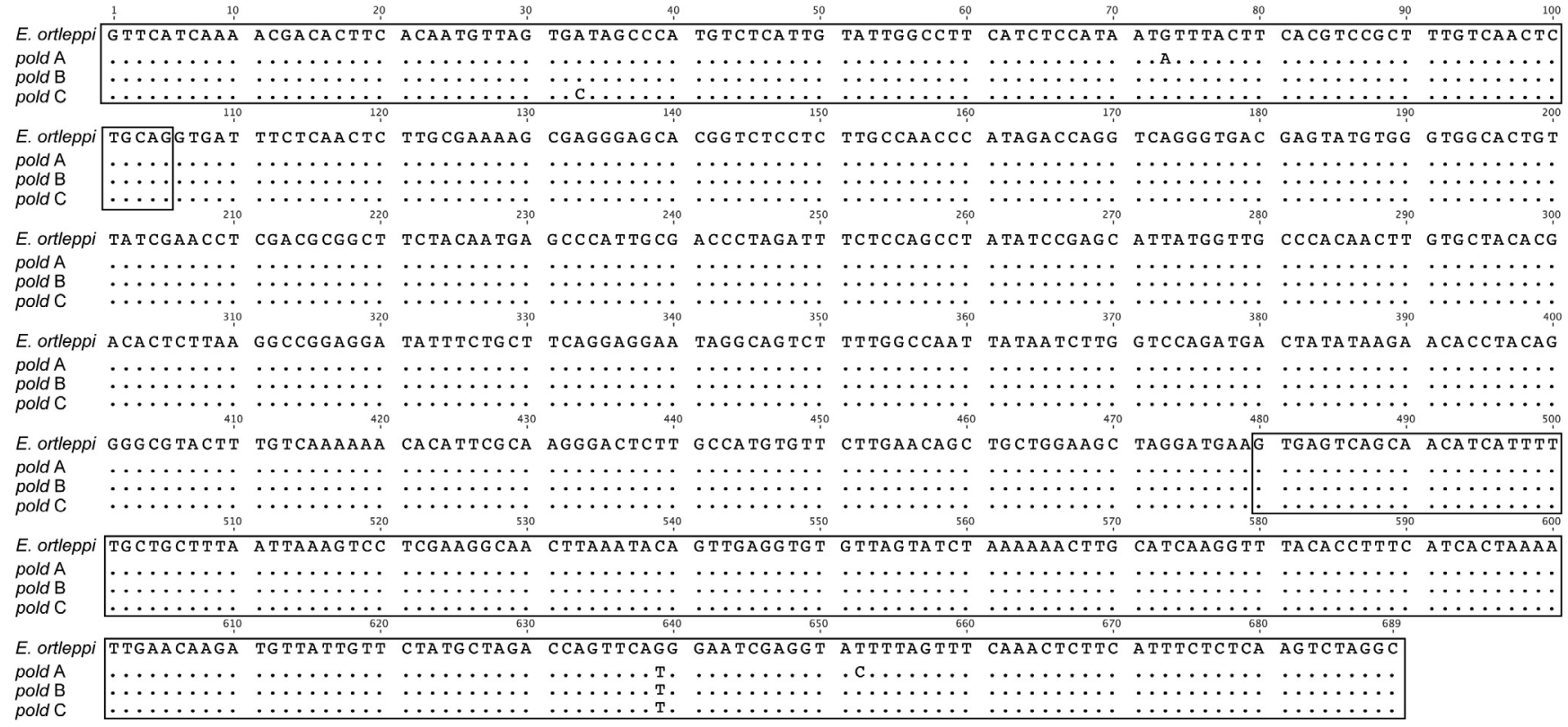

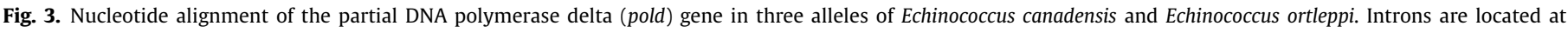
nucleotide positions of 1-105 and 480-689 (framed boxes in the alignment).

region of Russia and a reindeer in the Russian Far East. Haplotype BA was unique to G7 in pig, and confirmed in geographically separated Poland and Peru. Haplotype CB and EC were both shared by G8 and G10 obtained from moose and wolves, but the geographical distribution was markedly different. CB was distributed in Alaska and the northern Europe, while EC was found in the Far East Russia and Mongolia. Haplotypes DB and EB were obtained only from G10, and their distributions were confined to Alaska and the Russian Far East, respectively.

\subsection{Retrospective analysis of archival specimens}

To clarify the specific status of E. canadensis and E. borealis, we attempted sequencing to provide genetic information from formalin-fixed archival specimens held in the former USNPC. Separate lots of strobilate adult cestodes represent the type specimens attributed to E. granulosus borealis and E. granulosus canadensis des- ignated by Sweatman and Williams (1963). Two lots with numerous specimens are held, and represent the outcome of experimental infections in domestic dogs based on natural infections of hydatid metacestodes derived, respectively, from moose (Ontario, Canada) and semi-domestic reindeer (Aklavik, Northwest Territories, Canada). More than 10 combinations of the primers (Supplementary Table S1) were examined for the PCR using template DNAs extracted from the archival specimens, but none of them could yield amplicons except for the positive control.

\section{Discussion}

Due to the diversity of mitochondrial lineages, and in the absence of clear morphological attributes, the taxonomy of $E$. canadensis remains a controversial issue, i.e. whether this taxon, as currently understood, consists of a single or multiple species. 

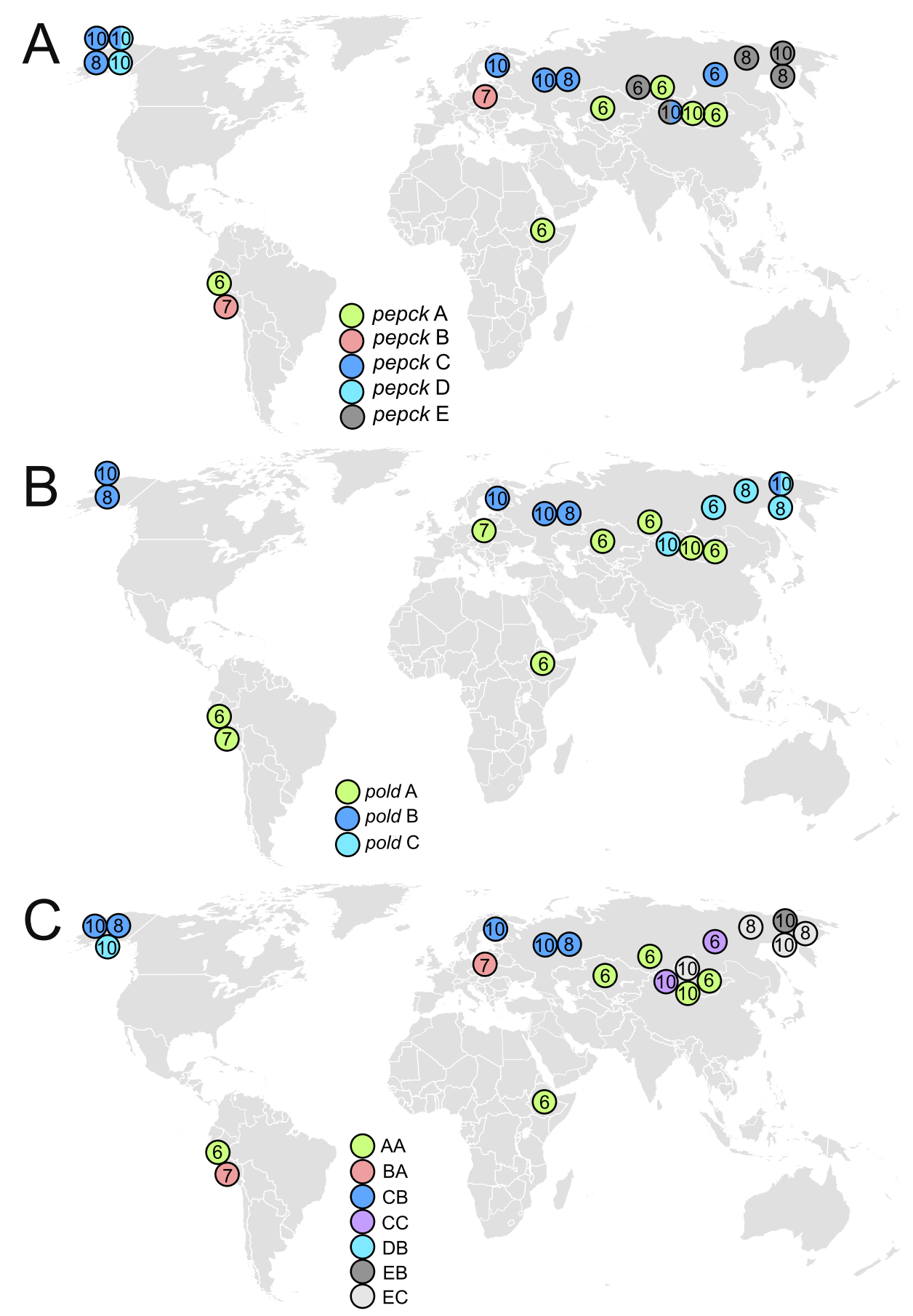

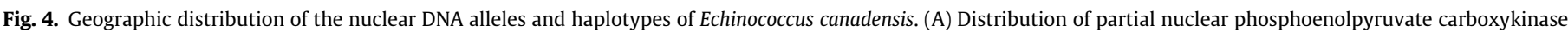

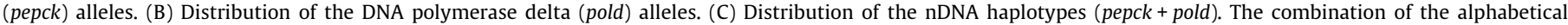
numbers of pepck and pold alleles are used to show the combined data of both loci (e.g., AA = pepck A and pold A). Numbers in circles show the mtDNA lineages.

In the present study, we attempted to subject specimens designated in the type series of E. granulosus canadensis and E. granulosus borealis to mtDNA analysis to shed light on the specific status of $E$. canadensis. Unfortunately, we could not obtain any positive results from PCR, due to the possible degradation of DNA during the longterm preservation in formalin and recently in ethanol. Therefore, our approach was to infer the specific status of $E$. canadensis by the analysis of recently obtained specimens using a combination of mtDNA and nDNA markers.

Phylogenetic analysis based on the complete cox1 sequences clearly showed that the E. canadensis isolates from a variety of hosts were divided into three monophyletic mtDNA clades, which correspond to G6/G7, G8 and G10. It was also clear that G6/G7 and G10 are sister to each other. Thus, from a molecular cladistic viewpoint, E. canadensis can be treated as two (G6/G7 and G10 versus $\mathrm{G} 8$ ) or three (G6/G7 versus G10 versus G8) maternal lineages. The genetic distance between G6/G7 and G10 (1.8-2.2\%) is not markedly smaller than that between G6/G7 and G8 (2.7-3.5\%) or G10 and G8 (2.7-3.6\%), supporting the three maternal lineages.

Because G6/G7 and G10 shared a most recent common ancestor, paraphyly of the lineages utilising northern free-ranging wild cervids as the intermediate hosts (G8 and G10) was demonstrated 
again (Lavikainen et al., 2006; Moks et al., 2008; Nakao et al., 2013a, b). The isolates obtained from pigs, representing G7 (pig strain), clustered in a monophyletic clade, but it was nested among the isolates of G6. The intermediate host ecology is different between G6/G7 (camel, goat and pig; domestic phylogenetically unrelated ungulates) versus G10 and G8 (wild or semi-domestic cervids), although there is some overlap since G6 has been reported in reindeer (Konyaev et al., 2013).

Lymbery et al. (2015a) proposed to designate the three lineages as Echinococcus intermedius (G6/G7), Echinococcus borealis (G8) and E. canadensis (G10). The resurrection and application of E. intermedius was rejected by Nakao et al. (2015) based on the arbitrary nature of this nomenclatural proposal, an absence of clear provenance, and lack of unequivocal type or voucher specimens archived in any global museum repository. In response to this opinion, Lymbery et al. (2015b) stressed the importance of considering the differences in morphology, life-history and evolutionary trajectories for respective mitochondrial lineages within E. canadensis. We agree that the phenotypic and mtDNA phylogenetic evidence shows that the lineages had experienced divergent evolutionary histories, but the status as discrete taxa has not been unequivocally resolved and requires clear criteria for species delimitation which combines phylogenetic (historical), ecological and biogeographic components (e.g., Brooks and McLennan, 2002). Lymbery (2017) proposed the application of the evolutionary species concept, which consists of two steps. The first step is the phylogenetic reconstruction to identify putative species which should be monophyletic and exclusive. The second step is to assess whether the members of the putative species possess genetic exchangeability or ecological exchangeability. Conversely, lack of any degree of exchangeability among groups in sympatry would indicate that those groups are different species. Thus, to elucidate the specific status of $E$. canadensis, genetic characterisation using nDNA markers is essential.

In the present study, two single copy nDNA gene markers were examined. Both pepck and pold genes have previously been used as genetic markers to infer the phylogeny of taeniid tapeworms (Knapp et al., 2011). In addition, the pold gene has been demonstrated to be useful to evaluate hybridisation in taeniid tapeworms (Yamane et al., 2013; Yanagida et al., 2014). Based on our current evaluations, from a total of 48 E. canadensis isolates, five and three alleles were identified at pepck and pold, respectively, and each allele generally showed affinity to a particular spectrum of host animals. None of these alleles was confirmed in the other Echinococcus spp., but only one isolate was available for each species. When we focus on the parasite isolates collected from the intermediate hosts, nDNA alleles were clearly classified to the alleles obtained from domestic animals such as camel, goat and pig ("southern domestic alleles": pepck A, pepck B and pold A) and those from wild or semi-wild cervids ("northern sylvatic alleles": pepck C, D, E and pold B and C) (Table 1). Although it is supposed that the two nuclear loci are not necessarily related directly to the host specificity, these results suggest the existence of genetic lineages adapted to certain intermediate hosts and life cycles, or may reflect other historical factors involved in isolation or connectivity. Concurrently most of the alleles, however, were shared among the parasite isolates belonging to the different mtDNA lineages. Some of them (pepck C, E and pold C) were found in G6, G8 and G10. The allele sharing among the different mitochondrial lineages was more evident where the different mtDNA lineages occur in sympatry, such as in Mongolia and Asian Russia, the Russian Far East and, concerning G8 and G10, across the Holarctic. Besides, in Mongolia, the Russian Far East and Alaska, heterozygotes were found at either locus.
These results strongly suggest that cross-fertilisation between individual adult worms belonging to the different mitochondrial lineages occurred in the past, after the divergence of the lineages. Cestodes are hermaphroditic, and both self- and crossfertilisation are possible. In the case of E. granulosus, the frequency of outcrossing was estimated to be as high as $74 \%$ (Haag et al., 2011). Hybridisation among closely related species or intraspecific genetic lineages has been demonstrated in other taeniid tapeworms such as between Taenia asiatica and Taenia saginata (Okamoto et al., 2010; Yamane et al., 2012, 2013), and between two genotypes of Taenia solium (Yanagida et al., 2014). G6, G8 and G10 of E. canadensis have common definitive hosts, wolves and dogs, and thus genetic mixing is quite possible in the regions where the domestic or semi-domestic livestock and wildlife coexist. It is likely that these genetic lineages possess both genetic and ecological exchangeability.

The most intriguing specimen, G6 from a reindeer in the Russian Far East, possessed "sylvatic alleles" at both pepck and pold loci. The mechanism of host specificity in Echinococcus spp. is not known, but it is reasonable to presume that it is under the control of nDNA. Therefore, although the mtDNA lineages generally correspond to their intermediate host affinity, this result indicates the potential risk of making a wrong estimation in the transmission ecology of CE caused by E. canadensis, when only using mtDNA genotyping. In the present study, nuclear-mitochondrial discordance was also observed in the adult worms collected from wolves in Mongolia and Asian Russia (Altai region). Two worms of G10 in Mongolia had "domestic alleles" at both nuclear loci. In contrast, "sylvatic allele" at the pepck locus was found from a worm of G6 in Asian Russia. Given that the above-mentioned G6 isolate with "sylvatic alleles" was found in reindeer, it is suggested that the G10 isolate with "domestic alleles" and the G6 isolate with "sylvatic alleles" were acquired by the wolves through the consumption of intermediate hosts which did not correspond to ungulates estimated by the mtDNA genotyping.

The present nDNA data show that pepck and pold alleles are shared among the isolates of G8 and G10 in Alaska and northern Europe, whereas the different alleles were confirmed from the population in the Russian Far East (Fig. 4). Based on the mtDNA phylogeny, it is obvious that G8 and G10 have demonstrated divergent trajectories and a shallow history of common ancestry in the Holarctic. Considering both mtDNA and nDNA data obtained in this study, the divergence between G8 and G10 probably occurred by geographic isolation in the Arctic across the Beringian nexus since the Last Glacial Maximum (LGM) and termination of the Pleistocene no deeper than 11 kiloyears before present (e.g., Hoberg et al., 2012, 2017). Geographic expansion and establishment may have been mediated by canid definitive hosts, or ungulates (particularly moose) which arrived very late in the Nearctic to become initially established in Alaska, and subsequently further eastward through post-glacial expansion following the LGM (Hundertmark et al., 2002). Although continuity of Eurasian and Nearctic populations of these parasites may extend deeper into the late Pleistocene, considerably greater levels of genetic divergence might be predicted in such a situation.

Events of natural expansion associated with free-ranging assemblages of hosts and parasites account for some component of the current distribution. Subsequently, it is apparent that anthropogenic drivers and introduction with reindeer from Palearctic sources during the last century have secondarily influenced the structure of a mosaic parasite fauna, now with extensive overlap in North America (e.g., Hoberg, 2010). Further, that G6/G7 are identical based on hydatid material from Poland and Peru is indicative of the role of long-range translocation and introduction 
either with dogs, or with infected ungulate intermediate hosts following European contact in the 1500s, or later. Generally, this history is consistent with the role of trade and European exploration in widespread dissemination, introduction and establishment of Echinococcus genetic lineages and species globally.

When a new species is erected or the validity of a known species is confirmed, the evidence for species boundaries or limits, which are linked to morphology, ecology, biogeography, genetics, and evolution should be demonstrated (e.g., Brooks and McLennan, 2002). In the case of morphologically indistinguishable cryptic species complexes, molecular phylogeography and population genetics play a key role in judging the validity of species. Based on an evolutionary species concept, Lymbery et al. (2015a) argued that E. canadensis should be split into three species, depending on their host specificities and distributional patterns. However, based on the exploration of mtDNA and nDNA in the current study, it is likely that $E$. canadensis individual tapeworms of G6/G7, G8 and G10 possess genetic exchangeability and that hybridisation occurs when they occur in sympatry, resulting from natural or anthropogenic drivers. Besides, it is natural to consider that there is an ecological exchangeability between G8 and G10 because they share both definitive and intermediate hosts distributed in sympatry (Lavikainen et al., 2003; Thompson et al., 2006; Schurer et al., 2013). Further, there is no basis for recognition of different lineages of North American and Eurasian origin since both G8 and G10 are widely distributed across the Holarctic. Therefore, it is not appropriate to treat each mitochondrial lineage of $E$. canadensis as an independent species. Herein, we propose to treat all G6/G7, G8 and G10 as a single species, E. canadensis. However, we also agree that there is a continuing necessity for differentiating the genetic lineages of the species showing different biological features, as stressed by Lymbery et al. (2015b). For epidemiological purposes, the traditional use of both mtDNA lineages and strains can be continued. However, "Fennoscandian cervid strain" seems to be an inappropriate name for G10 as it is distributed across the Holarctic and it is unlikely that it originates in northwestern Europe. At present, mtDNA lineages of G6, G7, G8 and G10, and "camel and goat strain", "pig strain" and "cervid strain" are preferable terms.

Although it is likely that the nuclear-mitochondrial discordance confirmed in this study reveals a genetic exchangeability among the mitochondrial lineages of $E$. canadensis, another explanation is also possible. If the nDNA allele polymorphism occurred before the divergence of the E. canadensis lineages or even earlier, some nuclear alleles could be shared by different lineages or Echinococcus spp. However, it is reasonable to assume that the divergence of "domestic alleles" and "sylvatic alleles" resulted from the divergence of G6/G7 and G10, and could be associated with processes of domestication of dogs or ruminants starting nearly 14-15 thousand years ago (Shannon et al., 2015; Orland, 2016), because these alleles generally show affinities to particular hosts. Considering the mtDNA phylogeny, separation of G8 should have preceded the divergence of "domestic" and "sylvatic" alleles. Therefore, it is not likely that the current allele polymorphism directly reflects the ancient polymorphism before the divergence of the lineages. However, to demonstrate the genetic exchangeability among the mitochondrial lineages of E. canadensis more objectively, statistical analyses using a greater number of nDNA gene markers and parasite isolates are needed. Lymbery (2017) also proposed the application of a coalescent-based approach to species delimitation among E. ortleppi and E. canadensis lineages. However, in the present study, we could not acquire a sufficient number of parasite isolates to conduct objective statistical analyses at any localities. Genomic data is not available for $E$. canadensis, however, these data for $E$. granulosus and E. multilocularis can facilitate establishment of new nDNA markers. Further intensive sampling of parasite isolates and investigation of the nDNA allelic polymorphism of both $E$. canadensis and E. ortleppi are essential in arriving at a complete understanding of the history of distribution and evolution for the former species. The history of $E$. canadensis, and identification of the factors linked to distribution and host association, have been complex, reflecting considerable faunal mixing extending across ecological time and concurrently influenced by natural expansion and human-caused invasions and introductions. If the genetic exchangeability among the mitochondrial lineages of $E$. canadensis is completely demonstrated, the morphological discrimination of the E. canadensis mitochondrial lineages (e.g., Lymbery et al., 2015a) will be ineffective in diagnosing discrete species.

\section{Acknowledgements}

The authors would like to acknowledge the technical expertise of The DNA Core facility of the Center for Gene Research, Yamaguchi University, Japan, supported by a grant-in-aid from the Ministry of Education, Science, Sports and Culture of Japan. We also would like to acknowledge the technical support of Shin-ichi Chiba (Center for Advanced Research and Education, Asahikawa Medical University, Japan). We thank Antti Oksanen (Finnish Food Safety Authority Evira) and Chinchuluun Boldbaatar (Institute of Veterinary Medicine, Ulaanbaatar, Mongolia) for providing specimens for this study. This study was supported by Grant-in-Aid for Scientific Research (No. 22590376) from Japan Society for the Promotion of Science (JSPS) to M. N., by RFBR research project (Nos. 13-0492107 and 13-04-10140) to S. K. and by Grants-in-Aid for Scientific Research (Nos. 21256003 and 24256002) from JSPS, JSPS-Asia/ Africa Scientific Platform Fund (2006-2011) and the Special Coordination Fund for Promoting Science and Technology from the Ministry of Education, Culture, Sports, Science and Technology in Japan (MEXT) (2010-2012) to A. I.

\section{Appendix A. Supplementary data}

Supplementary data associated with this article can be found, in the online version, at http://dx.doi.org/10.1016/j.ijpara.2017.07. 001.

\section{References}

Bowles, J., McManus, D.P., 1993. Molecular variation in Echinococcus. Acta Trop. 53, 291-305.

Bowles, J., Blair, D., McManus, D.P., 1992. Genetic variants within the genus Echinococcus identified by mitochondrial DNA sequencing. Mol. Biochem. Parasitol. 54, 165-174.

Bowles, J., Blair, D., McManus, D.P., 1994. Molecular genetic characterization of the cervid strain ("northern form") of Echinococcus granulosus. Parasitology 109, 215-221.

Brooks, D.R., McLennan, D.A., 2002. The Nature of Diversity: An Evolutionary Voyage of Discovery. University of Chicago Press, Chicago, IL, USA.

Cameron, T.W.M., 1960. The incidence and diagnosis of hydatid cyst in Canada. Echinococcus granulosus var. canadensis. Parassitologia 2, 381-390.

Eckert, J., Gemmell, M., Meslin, F., Pawlowski, Z., 2001. WHO/OIE manual on echinococcosis in human and animals: a public health problem of global concern. World Organization for Animal Health, Paris, France.

Haag, K.L., Marin, P.B., Graichen, D.A.S., De La Rue, M.L., 2011. Reappraising the theme of breeding systems in Echinococcus: is outcrossing a rare phenomenon? Parasitology 138, 298-302.

Himsworth, C.G., Jenkins, E., Hill, J.E., Nsungu, M., Ndao, M., Thompson, R.C.A., Covacin, C., Ash, A., Wagner, B.A., McConnell, A., Leighton, F.A., Skinner, S., 2010. Emergence of sylvatic Echinococcus granulosus as a parasitic zoonosis of public health concern in an indigenous community in Canada. Am. J. Trop. Med. Hyg. $82,643-645$.

Hoberg, E.P., 2010. Invasive processes, mosaics and the structure of helminth parasite faunas. Rev. Sci. Tech. 29, 255-272.

Hoberg, E.P., Galbreath, K.E., Cook, J.A., Kutz, S.J., Polley, L., 2012. Northern hostparasite assemblages: history and biogeography on the borderlands of episodic climate and environmental transition. Adv. Parasitol. 79, 1-97.

Hoberg, E.P., Cook, J.A., Agosta, S.J., Boeger, W., Galbreath, K.E., Laaksonen, S., Kutz, S. J., Brooks, D.R., 2017. Arctic systems in the Quaternary: Ecological collision, 
faunal mosaics and the consequences of wobbling climate. J. Helminthol. 91, 409-421.

Hundertmark, K.F., Shields, G.F., Udina, I.G., Boyer, R.T., Danilkin, A.A., Schwartz, C.C., 2002. Mitochondrial phylogeography of moose (Alces alces): late pleistocene divergence and population expansion. Mol. Phylogenet. Evol. 22, 375-387.

Hüttner, M., Nakao, M., Wassermann, T., Siefert, L., Boomker, J., Dinkel, A., Sako, Y., Mackenstedt, U., Romig, T., Ito, A., 2008. Genetic characterization and phylogenetic position of Echinococcus felidis (Cestoda: Taeniidae) from the African lion. Int. J. Parasitol. 38, 861-868.

Ito, A., Chuluunbaatar, G., Yanagida, T., Davaasuren, A., Sumiya, B., Asakawa, M., Ki, T., Nakaya, K., Davaajav, A., Dorjsuren, T., Nakao, M., Sako, Y., 2013. Echinococcus species from red foxes, corsac foxes, and wolves in Mongolia. Parasitology 140, $1648-1654$.

Ito, A., Nakao, M., Lavikainen, A., Hoberg, E., 2017. Cystic echinococcosis: future perspectives of molecular epidemiology. Acta Trop. 165, 3-9.

Kimura, M., 1980. A simple method for estimating evolutionary rates of base substitutions through comparative studies of nucleotide sequences. J. Mol. Evol. $16,111-120$.

Knapp, J., Nakao, M., Yanagida, T., Okamoto, M., Saarma, U., Lavikainen, A., Ito, A 2011. Phylogenetic relationships within Echinococcus and Taenia tapeworms (Cestoda: Taeniidae): An inference from nuclear protein-coding genes. Mol Phylogenet. Evol. 61, 628-638.

Konyaev, S.V., Yanagida, T., Ingovatova, G.M., Shoikhet, Y.N., Nakao, M., Sako, Y., Bondarev, A.Y., Ito, A., 2012. Molecular identification of human echinococcosis in the Altai region of Russia. Parasitol. Int. 61, 711-714.

Konyaev, S.V., Yanagida, T., Nakao, M., Ingovatova, G.M., Shoykhet, Y.N., Bondarev, A. Y., Odnokurtsev, V.A., Loskutova, K.S., Lukmanova, G.I., Dokuchaev, N.E. Spiridonov, S., Alshinecky, M.V., Sivkova, T.N., Andreyanov, O.N., Abramov, S A., Krivopalov, A.V., Karpenko, S.V., Lopatina, N.V., Dupal, T.A., Sako, Y., Ito, A. 2013. Genetic diversity of Echinococcus spp. in Russia. Parasitology 140, $1637-$ 1647.

Larkin, M.A., Blackshields, G., Brown, N.P., Chenna, R., McGettigan, P.A., McWilliam, H., Valentin, F., Wallace, I.M., Wilm, A., Lopez, R., Thompson, J.D., Gibson, T.J. Higgins, D.G., 2007. Clustal W and Clustal X version 2.0. Bioinformatics 23, 2947-2948.

Lavikainen, A., Lehtinen, M., Meri, T., Hirvelä-Koski, V., Meri, S., 2003. Molecular genetic characterization of the Fennoscandian cervid strain, a new genotypic group (G10) of Echinococcus granulosus. Parasitology 127, 207-215.

Lavikainen, A., Lehtinen, M., Laaksonen, S., Ågren, E., Oksanen, A., Meri, S., 2006. Molecular characterization of Echinococcus isolates of cervid origin from Finland and Sweden. Parasitology 133, 565-570.

Lymbery, A.J., 2017. Phylogenetic pattern, evolutionary processes and species delimitation in the genus Echinococcus. Adv. Parasitol. 95, 111-145.

Lymbery, A.J., Jenkins, E.J., Schurer, J.M., Thompson, R.C.A., 2015a. Echinococcus canadensis, E. borealis, and E. intermedius. What's in a name? Trends Parasitol. $31,23-29$.

Lymbery, A.J., Jenkins, E.J., Schurer, J.M., Thompson, R.C.A., 2015b. Response to Nakao et al. - is Echinococcus intermedius a valid species? Trends Parasitol. 31, 343-344.

Moks, E., Jogisalu, I., Valdmann, H., Saarma, U., 2008. First report of Echinococcus granulosus G8 in Eurasia and a reappraisal of the phylogenetic relationships of "genotypes" G5-G10. Parasitology 135, 647-654.
Nakao, M., Lavikainen, A., Hoberg, E., 2015. Is Echinococcus intermedius a valid species? Trends Parasitol. 31, 342-343.

Nakao, M., McManus, D., Schantz, P., Craig, P., Ito, A., 2007. A molecular phylogeny of the genus Echinococcus inferred from complete mitochondrial genomes. Parasitology 134, 713-722.

Nakao, M., Lavikainen, A., Yanagida, T., Ito, A., 2013a. Phylogenetic systematics of the genus Echinococcus (Cestoda: Taeniidae). Int. J. Parasitol. 43, 1017-1029.

Nakao, M., Yanagida, T., Konyaev, S., Lavikainen, A., Odnokurtsev, V.A., Zaikov, V.A. Ito, A., 2013b. Mitochondrial phylogeny of the genus Echinococcus (Cestoda: Taeniidae) with emphasis on relationships among Echinococcus canadensis genotypes. Parasitology 140, 1625-1636.

Okamoto, M., Nakao, M., Blair, D., Anantaphruti, M.T., Waikagul, J., Ito, A., 2010. Evidence of hybridization between Taenia saginata and Taenia asiatica. Parasitol. Int. 59, 70-74.

Orland, L., 2016. Back to the roots and routes of dromedary domestication. P. Natl. Acad. Sci. USA 113, 6588-6590.

Rausch, R.L., 2003. Cystic echinococcosis in the Arctic and Sub-Arctic. Parasitology 127 (Suppl.), S73-S85.

Schurer, J., Shury, T., Leighton, F., Jenkins, E., 2013. Surveillance for Echinococcus canadensis genotypes in Canadian ungulates. Int. J. Parasitol. Parasites Wildl. 2, 97-101.

Shannon, L.M., Boyko, R.H., Castelhano, M., Elizabeth, C., Hayward, J.J., McLean, C., White, M.E., Abi Said, M., Anita, B.A., Bondjengo, N.I., Calero, J. Galov, A. Hedimbi, M., Imam, B., Khalap, R., Lally, D., Masta, A., Oliveira, K.C., Pérez, L., Julia, R., Tam, N.M., Truillo-Cornejo, F.J., Valeriano, C., Sutter, N.B., Todhunter, R. J., Bustamante, C.D., Boyko, A.R., 2015. Genetic structure in village dogs reveals a Central Asian domestication origin. Proc. Natl. Acad. Sci. U.S.A. 112, 1363913644.

Sweatman, G.K., Williams, R.J., 1963. Comparative studies on the biology and morphology of Echinococcus granulosus from domestic livestock, moose and reindeer. Parasitology 53, 339-390.

Swofford, D.L., 2002. PAUP*: phylogenetic analysis using parsimony, version 4.0b10. Sinauer Associates, Massachusetts, USA.

Tamura, K., Stecher, G., Peterson, D., Filipski, A., Kumar, S., 2013. MEGA6: molecular evolutionary genetics analysis version 6.0. Mol. Biol. Evol. 30, 2725-2729.

Thompson, R.C.A., McManus, D.P., 2002. Towards a taxonomic revision of the genus Echinococcus. Trends Parasitol. 18, 452-457.

Thompson, R.C.A., Boxell, A.C., Ralston, B.J., Constantine, C.C., Hobbs, R.P., Shury, T., Olson, M.E., 2006. Molecular and morphological characterization of Echinococcus in cervids from North America. Parasitology 132, 439-447.

Yamane, K., Suzuki, Y., Tachi, E., Li, T., Chen, X., Nakao, M., Nkouawa, A., Yanagida, T., Sako, Y., Ito, A., Sato, H., Okamoto, M., 2012. Recent hybridization between Taenia asiatica and Taenia saginata. Parasitol. Int. 61, 351-355.

Yamane, K., Yanagida, T., Li, T., Chen, X., Dekumyoy, P., Waikagul, J., Nkouawa, A., Nakao, M., Sako, Y., Ito, A., Sato, H., Okamoto, M., 2013. Genotypic relationships between Taenia saginata, Taenia asiatica and their hybrids. Parasitology 140, 1595-1601.

Yanagida, T., Carod, J.F., Sako, Y., Nakao, M., Hoberg, E.P., Ito, A., 2014. Genetics of the pig tapeworm in Madagascar reveal a history of human dispersal and colonization. PLoS One 9, e109002. 